\title{
CHARACTERIZATION OF SYNTHESIZED POLYMERIC BLEND MEMBRANES ENHANCED BY METHYL DIETHANOLAMINE FOR EFFICIENT $\mathrm{CO}_{2}$ SEPARATION
}

\author{
Asim Mushtaq ${ }^{1,2,}$, Hilmi Bin Mukhtar ${ }^{1}$, Azmi Mohd Shariff $^{1}$
}

\begin{abstract}
The limited performance of pure glassy and rubbery polymeric membranes for natural gas purification are due to their intrinsic properties. Optimizing their properties by blending both polymers are expected to address the shortage. The foremost objective of this research is to synthesis enhance polymer blend membranes (EPBM) using glassy polysulfone (PSU) and rubbery polyvinyl acetate (PVAc) with the addition of amine for carbon dioxide $\left(\mathrm{CO}_{2}\right)$ removal from methane $\left(\mathrm{CH}_{4}\right)$. The EPBM were developed by varying the composition of PVAc ranging from 5 to 20 wt. \% with 95 to 80 wt. \% base PSU in dimethylacetamide (DMAc) solvent. The amines composition was added to the blend and kept at 10 wt. \% over solvent. The findings showed good miscibility between PSU and PVAc blends and the original functional groups of polymers and amines were shown by FTIR with very few spectral peak shifts. The synthesized EPBM were found to have homogenous surfaces and a packed bed sphere structure as shown by FESEM images. Increasing the composition of PVAc from 5 to $20 \mathrm{wt}$. \% has significantly reduced the glass transition temperature $\left(T_{g}\right)$ of PSU from $185.09^{\circ} \mathrm{C}$ to $155.75^{\circ} \mathrm{C}$.
\end{abstract}

Keywords: Carbon Dioxide, Methyl Diethanolamine, Polymeric Blend Membranes, Polysulfone, Polyvinyl Acetate

\section{INTRODUCTION}

The most corporate contaminant of natural gas is carbon dioxide and it must be removed to a minimum level of less than $2 \%$ to minimize pipeline corrosion. Until the overview of membrane technology, standard removal techniques utilized amine absorption. Membranes are the technology of best for $\mathrm{CO}_{2}$ removal systems for offshore platforms and are even beginning to compete head-to-head with amine structures at onshore plants. Membrane systems are skid mounted, so that scope, time and cost taken for site preparation are minimized. Installation costs are considerably lower than other technologies, particularly for offshore locations. Moreover, for water treatment and solvent storage no additional facilities are needed. Pure glassy and rubbery polymeric membranes are problematic in natural gas purification due to its physicochemical characteristics. The rubbery polymeric membranes are soft and flexible, also they operate above $T_{g}$ with high permeance, but low selectivity, whereas glassy polymeric membrane are rigid and operate below $T_{g}$ with low permeance but high selectivity. The $\mathrm{CO}_{2}$ interact more vigorously with rubbery polymers and exhibit high solubility [1-6].

With the purpose of optimize the benefits of both polymers, blending of glassy with rubbery polymers improve membrane properties for gas separation. Although, the polymeric blend membranes has many advantages in terms of thermal, chemical stability permeability and selectivity. To enhance the compatibility of polymer blend, a third component is added such as alkanolamine. It is expected that the addition of alkanolamine will improve the PBM properties as well as the gas separation performance [7-10].

Amine solutions help purify acidic natural gas. Alkanolamine removes $\mathrm{CO}_{2}$ from a gas stream via an exothermic reaction between $\mathrm{CO}_{2}$ and the functional group of amine in alkanol amine. Amine addition to the polymer blend may affect the polymer's capacity for absorption, and thus, allow enhanced permeability[11-13]. In EPBM fabrication, the appropriate control of morphological development obtains the homogeneity that avoids phase separation, which is highly important. EPBM fabrication proceeds with PSU-PVAc blended with different amines in a suitable solvent. Thus, by blending glassy with rubbery polymer using amine solution, the properties of membrane was also enhanced for the $\mathrm{CO}_{2} / \mathrm{CH}_{4}$ separation [14].

This paper was recommended for publication in revised form by Regional Editor N. Filiz Özdil

${ }^{1}$ Chemical Engineering Department, Universiti Teknologi PETRONAS, 32610 Bandar Seri Iskandar, Perak Darul Ridzuan, Malaysia.

${ }^{2}$ Polymer and Petrochemical Engineering Department, NED University of Engineering \& Technology, Karachi, Sindh, Pakistan.

*E-mail address: engrasimmushtaq@yahoo.com

Orcid id: 0000-0001-9930-436X, 0000-0002-1862-0924, 0000-0001-8524-1994

Manuscript Received 12 November 2019, Accepted 06 February 2020 


\section{METHODOLOGY}

\section{Materials and Method for Membrane Fabrication:}

Rubbery and glassy polymers were used to fabricate polymeric membrane films. The polysulfone (PSU) Udel ${ }^{\circledR}$ P-1800 was a powdered grade, glass transition temperature $\left(T_{g}\right)$ of $185^{\circ} \mathrm{C}$ was assimilated from Solvay Advanced Polymer; L.L.C, U.S. The polysulfone PSU polymer was selected mainly due to its ease of fabrication, good properties like high strength and good thermal stability associated with low cost and ease of availability. This material also offers very good control of pore size, pore size distribution, and good film-forming properties.

The polyvinyl acetate (PVAc) average molecular weight $\mathrm{M}_{\mathrm{w}} \sim 100,000$ beads were purchased from SigmaAldrich, Germany with a glass transition temperature $\left(T_{g}\right)$ of $28^{\circ} \mathrm{C}$. PVAc was selected due to its flexible strong bonding and non-acidic nature. The chemical structures of the both polymers are shown in Figure 1 [15-17]. The membrane structure and its performance are mostly affected by the selection of suitable solvent. After reviewing the literature on the solubility of PSU and PVAc polymers, dimethylacetamide (DMAc) solvent was selected by its properties. A dimethylacetamide (DMAc) solvent and methyl diethanolamine (MDEA) 99.99\% pure was acquired from Merck, Germany. The chemical structures are shown in Figure $1[16,18,19]$.

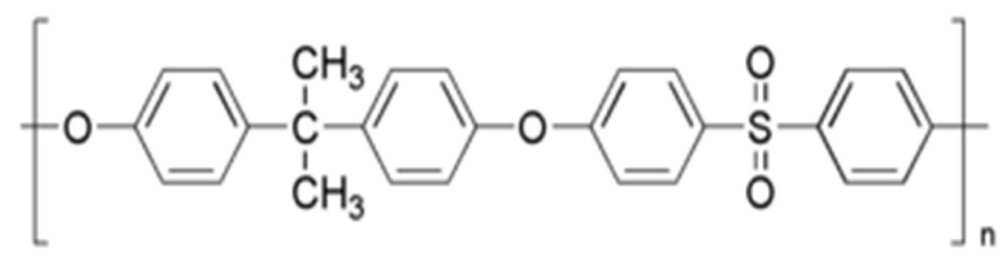

a)

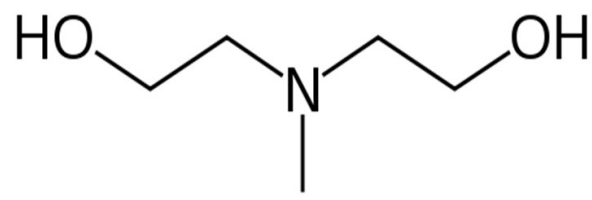

c)<smiles>CC(=O)OC(CC(C)(C)C)C(C)(C)C</smiles>

b)

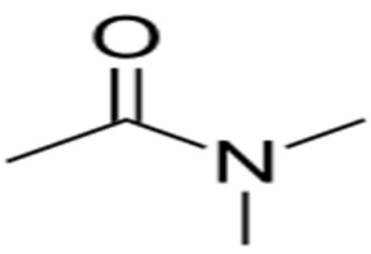

d)

Figure 1. Chemical structure a) polysulfone, b) polyvinyl acetate, c) methyl diethanolamine, d) dimethylacetamide

The polymer blend membrane was synthesized with different composition of PVAc and PSU in DMAc solvent. Firstly PVAc was dissolve in the DMAc solvent completely. At that time PSU polymer and MDEA amine was added. Stirring was continuous for 24 hours. Polymers and amine were dissolving in the solvent under continuous stirring at room temperature to get a homogeneous mixture. This blend commonly raised as the casting solution was synthesized by dissolving 20 wt. \% of polymer in the DMAc solvent to develop membranes with different compositions. To remove air bubbles form during blending the solution was allowed to immersion sonication in Transonic Digital S, Elma ${ }^{\circledR}$ for 3 hours at a frequency of $100 \mathrm{~Hz}$. Each polymer and amine was fully dissolved in the solvent and there were no signs of agglomeration upon erect the solution which showed that it was a miscible blend. This casting solution was cast on a glass plate with the help of $200 \mu \mathrm{m}$ opening casting knife. After 1 hour of evaporation, the film was dried in an oven at $70^{\circ} \mathrm{C}$ for 2 hours. These cast membranes were then drying in a room temperature for five days. These synthesized membranes were unpeeled from the glass plate for characterization (description). The configurations of synthesized polymeric blend membrane be present given in Table 1. 
Journal of Thermal Engineering, Research Article, Vol. 7, No. 2, Special Issue 13, pp. 71-82, February, 2021

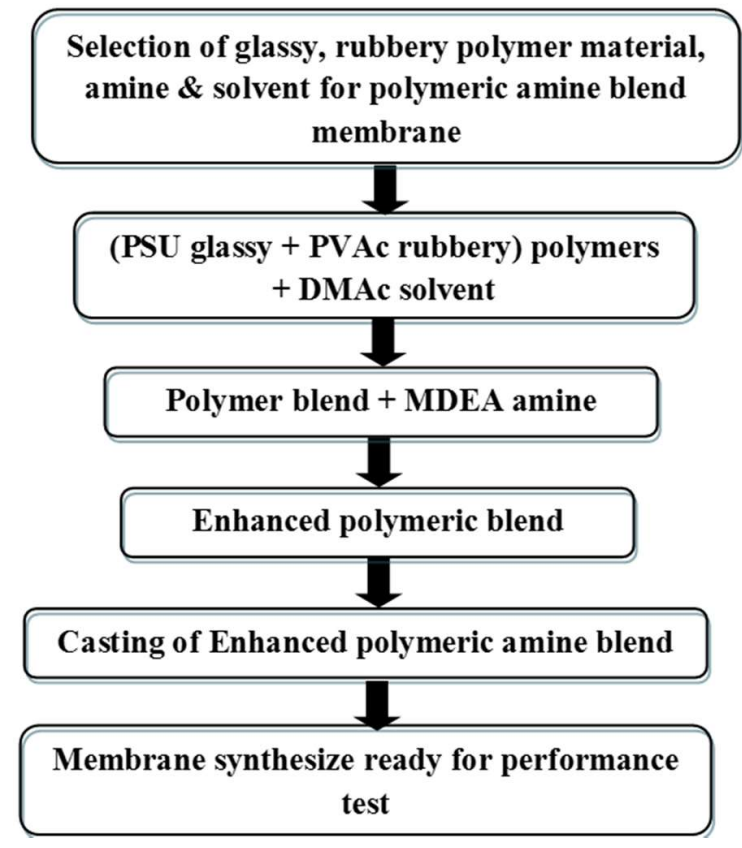

Figure 2. Research approach

Table 1. Different composition of polymeric blend membranes in DMAc solvent

\begin{tabular}{|c|c|c|c|}
\hline \multirow{2}{*}{ Membrane } & \multicolumn{2}{|c|}{ Polymer } & \multirow{2}{*}{$\begin{array}{c}\text { Amine 10\% } \\
\text { wt. \% }\end{array}$} \\
\cline { 2 - 3 } & PSU & PVAc & \\
\hline M1 & $100 \%$ & $0 \%$ & \multirow{2}{*}{-} \\
\hline M2 & $0 \%$ & $100 \%$ & \\
\hline M3 & $95 \%$ & $5 \%$ & \multirow{2}{*}{ MDEA } \\
\hline M4 & $90 \%$ & $10 \%$ & \\
\hline M5 & $85 \%$ & $15 \%$ & \\
\hline M6 & $80 \%$ & $20 \%$ & \\
\hline
\end{tabular}

\section{Field Emission Scanning Electron Microscope (FESEM)}

The membrane morphology (pore size distribution) of the polymer membrane, polymer blend membrane, amine polymer membrane and enhanced polymeric amine blend membrane were studied by Field Emission scanning Electron microscope (FESEM) instrument, SUPRA by ZEISS model 55VP. FESEM micrographs provide a qualitative assessment of membrane morphology and the homogeneity throughout the polymer matrix. The Supra55VP FESEM allows surface examination down to nanometer scales in either Variable Pressure (VP) model or high vacuum model and provide magnifying $2 \mathrm{~K}$ to $10 \mathrm{~K}$. To characterise the membrane film, the films were initially fractured cryogenically in liquid nitrogen, to get a clear cut of the cross section and mounted onto a circular stainless steel sample holder with an electrically conductive double sided tape. Immersing membrane film for several minutes in liquid nitrogen was necessary for the less brutal membrane. FESEM micrographs were examined using an accelerating voltage of $5 \mathrm{kV}$ with magnification; the surface view was at $500 \mathrm{X}$ and cross section view $200 \mathrm{X}$.

\section{Thermal Gravimetric Analysis (TGA)}

The Perkin Elmer TGA 7 Thermogravimetric analysis was used to determine the amount and rate of change in the sample weight as a function of time or temperature under controlled conditions. These measurements were 
mainly worked to measure the thermal stability of a material and compositions of their products along with used precursors. The TGA of the blended membranes sample, weighing about $10-15 \mathrm{mg}$ were run from ambient to $800^{\circ} \mathrm{C}$ at $10^{\circ} \mathrm{C} / \mathrm{min}$ varying heating rate of $20 \mathrm{~mL} / \mathrm{min}$ under a nitrogen atmosphere.

\section{Fourier Transform Infrared Spectroscopy (FTIR)}

Perkin Elmer Spectrum One FTIR Spectrometer was used to determine the functional group present in a molecule by observing the specific absorption of radiation by each molecule in the sample. FTIR analysis of developed polymeric blend membranes was examined the interaction between two polymers and amines. The scans were 20 with wavelength range $4000 \mathrm{~cm}^{-1}-450 \mathrm{~cm}^{-1}$ and spectra were gotten from a sampling area, diameter 200 -micrometer. The samples from the membrane were cut at random positions from developed membranes and then clamped to the plate. Using equipment software, the all spectra were rectified for the FTIR characteristic progressive rise in the absorbance at lower the wave numbers. The wavelength or the frequency of absorption rely on the relative mass and geometry of the atoms and the constant force between the bonds.

\section{RESULTS \& DISCUSSION}

\section{Morphology of Synthesized Enhanced Polymeric Blend Membranes}

The FESEM morphology of the top and cross-section view of PSU/PVAc/MDEA blend membranes with based polymeric membranes were compared. Figure 3 (a) shows that there were no microvoids, seen on the PSU surface. The cross section of based PSU membrane indicates that microporous structure was uniformly distributed with the sphere structure size of $16.68 \pm 3.35 \mu \mathrm{m}$ as illustrated in Figure 3 (b). This type of structure is known as packed bed of spheres [20]. Since PSU possesses the polar $-\mathrm{SO}_{2}-$ groups and rigid aromatic rings, caused the structure to be very rigid, chain motion is restricted to bond vibrations and coagulative, lead to the higher viscosity of casting solution [21]. Due to higher viscosity, such type of structure is formed in PSU membrane which is in accordance with the previous works [22].

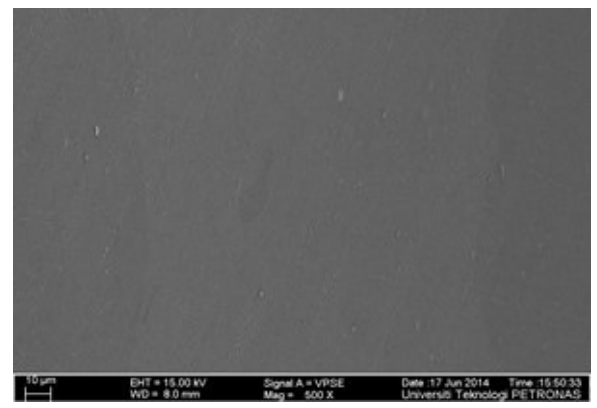

a)

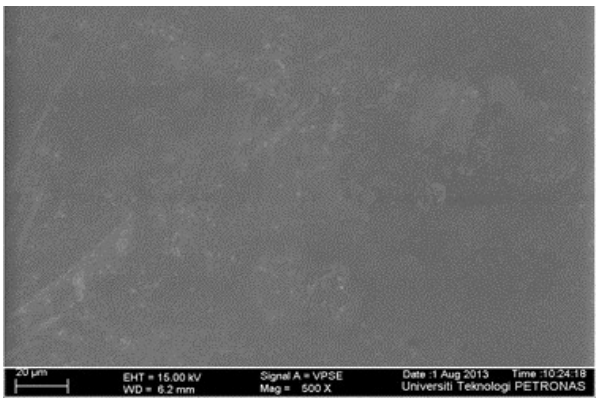

c)

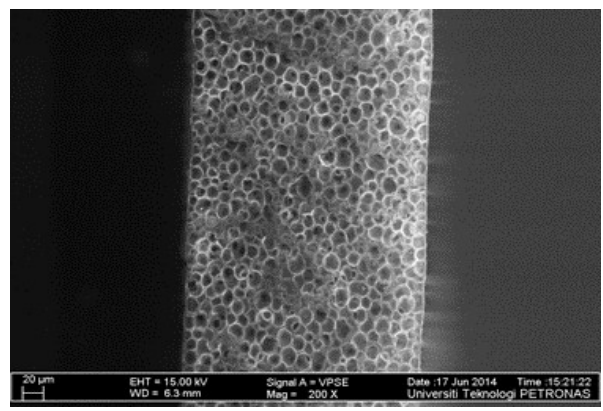

b)

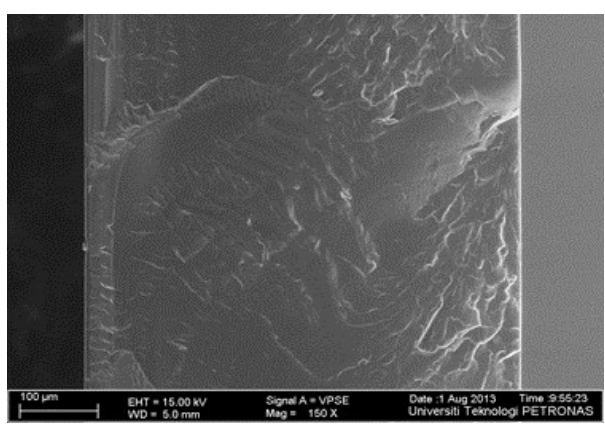

d)

Figure 3. a) Top view $(500 \mathrm{X})$, b) cross section view (200 X) of PSU based membrane and c) top view $(500 \mathrm{X}),(\mathrm{d})$ cross section view $(200 \mathrm{X})$ of PVAc based membrane 
The FESEM morphology of the based PVAc membrane is shown in Figure 3 (c). There was no crack or defect observed on the surface, resulting in a dense homogenous polymeric membrane. Figure 3 (d) shows that the PVAc possesses dense structure due to the absence of crystallinity, paucity of polar groups, and low degree of crosslinking. As a result of the presence of $\mathrm{C}=\mathrm{O}$ polar bonds of carbonyl groups in polyvinyl acetate and the phase behavior of $\mathrm{CO}_{2}$ exposed in polyvinyl acetate, leads to higher solubility of $\mathrm{CO}_{2}$.

Figure 4 and 5 shows the morphology of PSU with different compositions of PVAc and MDEA 10 wt.\% blended membrane. The top view of Figures $4(\mathrm{a}, \mathrm{c})$ and $5(\mathrm{a}, \mathrm{c})$ shows that membrane was effectively synthesised without any crack or defect. Their surfaces were uniform which affirmed the miscibility of both polymers with MDEA amine.

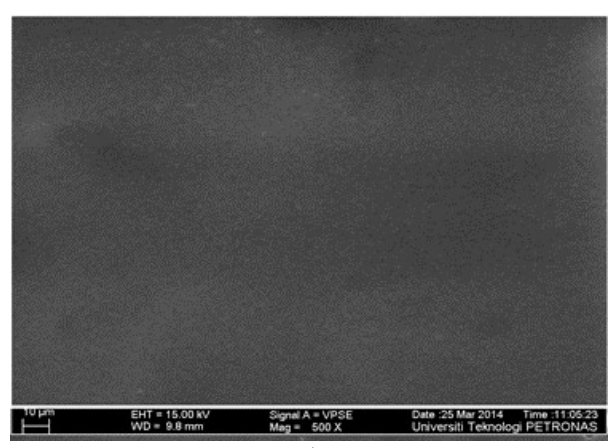

a)

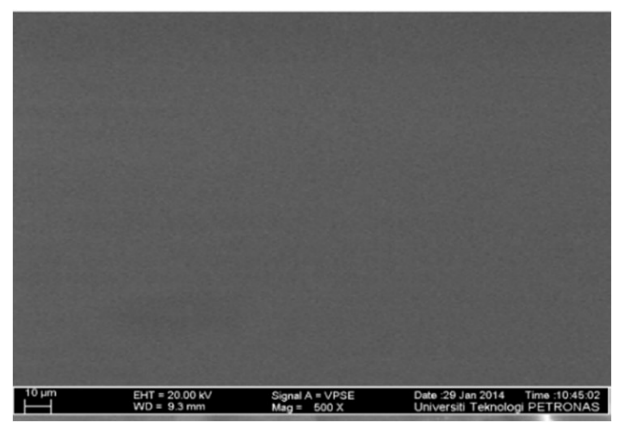

c)

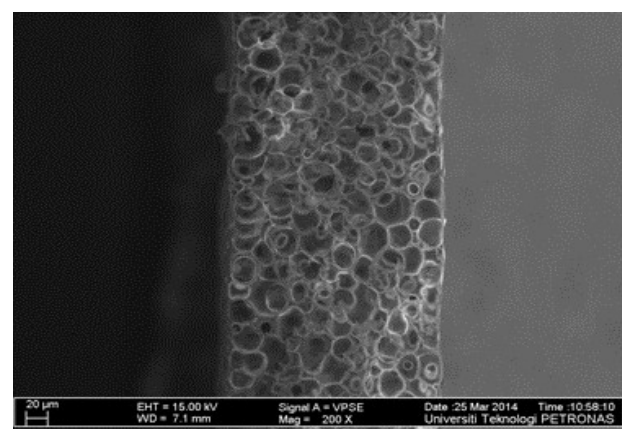

b)

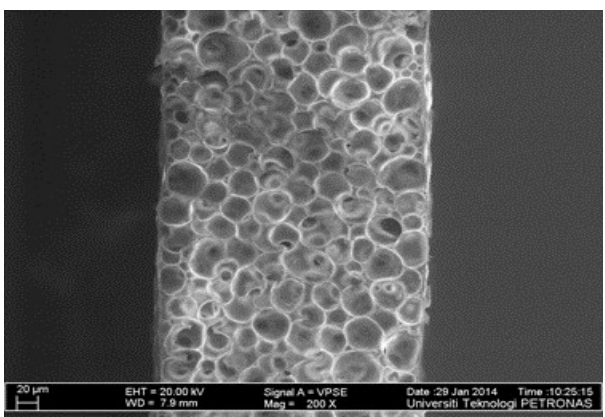

d)

Figure 4. a) Top view (500 X), b) cross section view (200 X) of blend membrane PSU 95\% / PVAc 5\% / MDEA and c) top view $(500 \mathrm{X}), \mathrm{d})$ cross section view $(200 \mathrm{X})$ of blend membrane PSU 90\% / PVAc 10\% / MDEA

Correspondingly, on comparing cross-sections: Figures $4(\mathrm{~b}, \mathrm{~d})$ and $5(\mathrm{~b}, \mathrm{~d})$ the blended polymeric membranes were highly packed with a uniform packed bed of sphere but the size was somewhat different due to different compositions of PVAc. For PSU/PVAc (95/5) and 10\% MDEA the microsphere size watched is $29.62 \pm 9.7 \mu \mathrm{m}$, for PSU/PVAc (90/10) and 10\% MDEA the structure size got to be $34.57 \pm 6.56 \mu \mathrm{m}$. Furthermore, when $15 \%$ PVAc was included in PSU with 10\% MDEA the packed bed of sphere size is $39.70 \pm 9.89 \mu \mathrm{m}$, as $20 \%$ PVAc was included the sphere size is $56.15 \pm 10.64 \mu \mathrm{m}$. Although various creations of PVAc, vinyl acetate derivation in PVAc has been ascribed to its huge free volume, which might be because of the adaptability of the vinyl acetate linkages in the polymer [23]. Alkanolamines arrangement consolidates the amine atoms into the aforesaid materials. These crosssections show well-blended interaction with microstructures between the PSU/PVAc polymers and MDEA amine.

The sphere size changes due to the increasing composition of PVAc. As vinyl acetate in PVAc has been accredited to its large free volume, cause due to the flexibility of the vinyl acetate linkages in the polymer chain [24]. Amine molecules dispersed in PSU/PVAc matrix. The most common specific intermolecular interactions occurring between polymer chains and amine are hydrogen bond, hydroxyl bond, ionic bond, and dipole-dipole interactions [25]. 
Journal of Thermal Engineering, Research Article, Vol. 7, No. 2, Special Issue 13, pp. 71-82, February, 2021

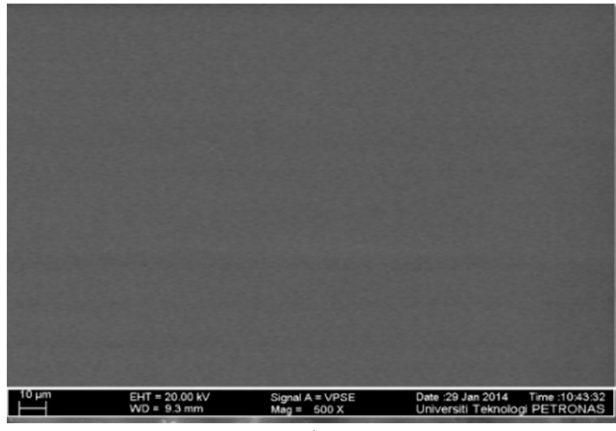

a)

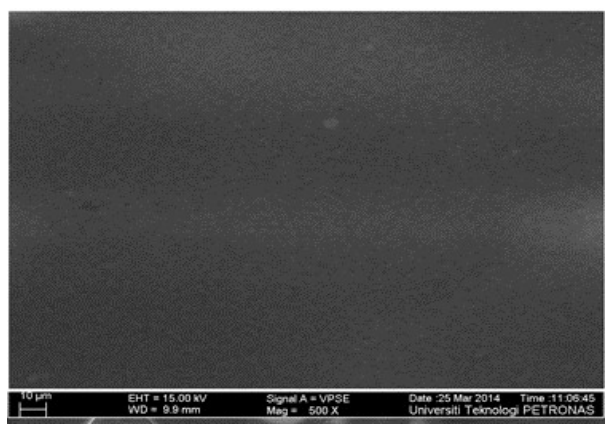

c)

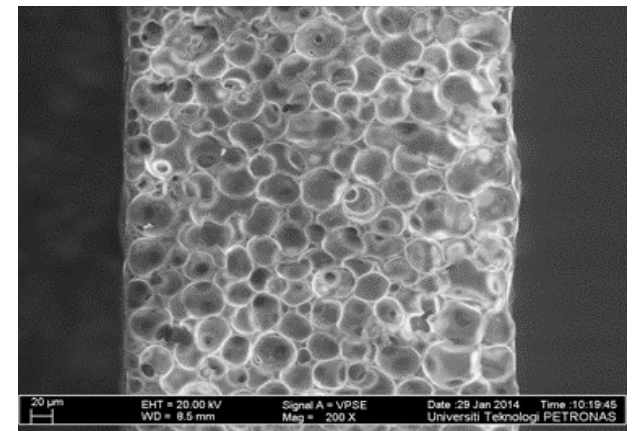

b)

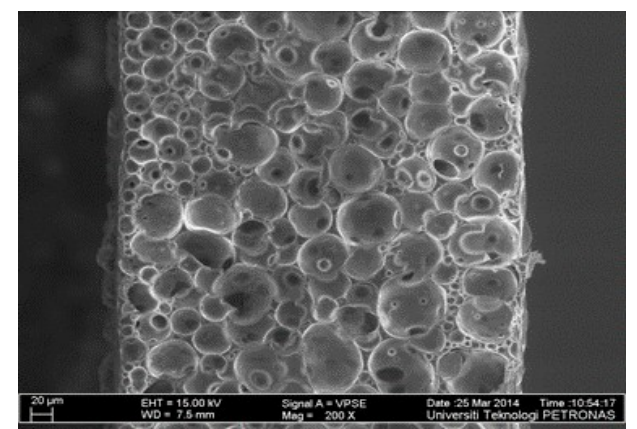

d)

Figure 5. a) Top view (500 X), b) cross section view (200 X) of blend membrane PSU 85\% / PVAc 15\% / MDEA and c) top view $(500 \mathrm{X}), \mathrm{d})$ cross section view $(200 \mathrm{X})$ of blend membrane PSU 80\% / PVAc 20\% / MDEA

\section{Thermal Gravimetric Analysis of Enhanced Polymeric Blend Membranes}

Figure 6 represents the TGA graph of based PSU and PVAc membranes, respectively. This figure shows that the PSU started to degrade at $535.13^{\circ} \mathrm{C}$ and thermal degradation ends on $570.48^{\circ} \mathrm{C}$. At these points, the polysulfone undergoes thermal decomposition that affords a variety of decomposition products including sulfur dioxide and alkenes. The weakest bond in a polysulfone chain is the C-S bond, due to the C-O bond [26].

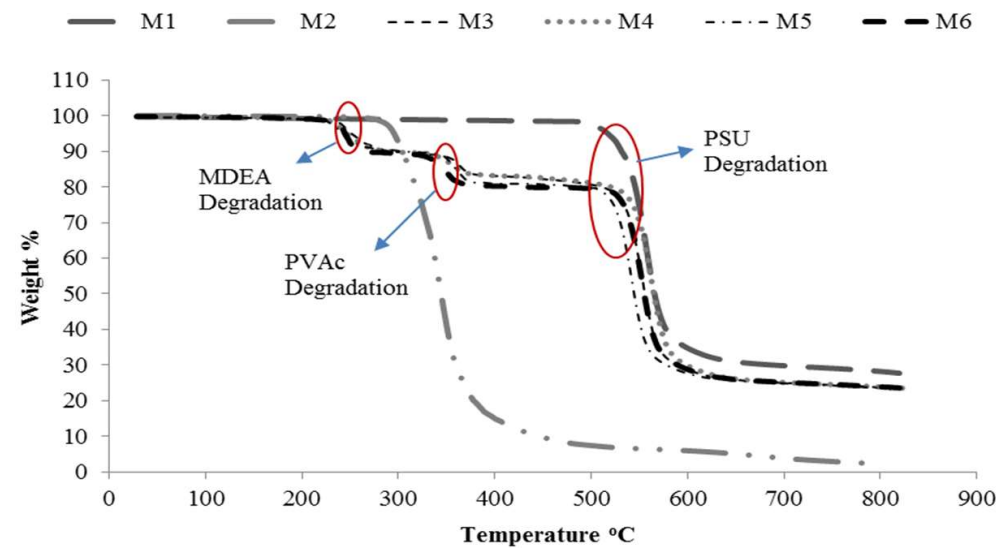

Figure 6. Effect of TGA on enhanced polymeric blend membranes with various composition of PVAc in PSU with MDEA amine

The PVAc membrane-initiated to degrade at $318.54^{\circ} \mathrm{C}$, and $355.38^{\circ} \mathrm{C}$ is the final degradation temperature. The mechanism of thermal degradation of polyvinyl acetate is a complex process including, among other, radical 
recombination, the chain fission, carbon-hydrogen single bond fission, radical addition and abstraction mild chain end chain scission. It also includes disproportionate conjugated double bond and hydrogen transfer formation a fusion of aromatic ring, aromatization, cyclisation, graphitization reactions and char formation [27, 28]. This figure also shows that the thermal degradation behaviour of enhanced polymeric blend membranes with MDEA amine. The adding MDEA $10 \mathrm{wt}$ \% to PSU/PVAc polymer blend, altered the thermal stability of both polymers. This figure shows for the M3 membrane, the constancy of the resultant blend changed to $533.29^{\circ} \mathrm{C}$ for PSU. Correspondingly, this trend was also similar for M4, M5, and M6 blend membranes. For M6, degradation onsets at $525.07^{\circ} \mathrm{C}$ and maximum degradation temperatures of $557.43^{\circ} \mathrm{C}$. The PSU chain contains $\mathrm{C}-\mathrm{O}$ bond and PVAc acetate group which interact $\mathrm{OH}^{-}$ group at low temperature on polymer side chains, followed by the breakdown of the polymer's backbone at higher temperatures [27, 29]. Table 2 summarises thermal degradation results.

Table 2. Summary of thermal gravimetric degradation temperature $\left(T_{g}\right)$ of enhanced polymeric blends membranes

\begin{tabular}{|c|c|c|c|c|c|c|c|c|c|}
\hline \multirow[b]{2}{*}{$\begin{array}{c}\text { Membrane } \\
\text { Sample }\end{array}$} & \multicolumn{3}{|c|}{ Polymer Blend } & \multirow{2}{*}{$\begin{array}{l}\text { Degradation } \\
\text { MDEA } \\
\text { Amine onset } \\
\text { temperature } \\
\quad\left({ }^{\circ} \mathrm{C}\right)\end{array}$} & \multirow{2}{*}{$\begin{array}{c}\text { Maximum } \\
\text { MDEA } \\
\text { Amine } \\
\text { degradation } \\
\text { temperature } \\
\left({ }^{\circ} \mathrm{C}\right)\end{array}$} & \multirow[b]{2}{*}{$\begin{array}{c}\text { Degradation } \\
\text { onset PVAc } \\
\text { temperature } \\
\left({ }^{\circ} \mathrm{C}\right)\end{array}$} & \multirow{2}{*}{$\begin{array}{c}\text { Maximum } \\
\text { degradation } \\
\text { PVAc } \\
\text { temperature } \\
\left({ }^{\circ} \mathrm{C}\right)\end{array}$} & \multirow[b]{2}{*}{$\begin{array}{c}\text { Degradation } \\
\text { onset PSU } \\
\text { temperature } \\
\left({ }^{\circ} \mathrm{C}\right)\end{array}$} & \multirow{2}{*}{$\begin{array}{c}\text { Maximum } \\
\text { degradation } \\
\text { PSU } \\
\text { temperature } \\
\left({ }^{\circ} \mathrm{C}\right)\end{array}$} \\
\hline & $\begin{array}{c}\text { PSU } \\
\text { wt/wt } \%\end{array}$ & $\begin{array}{c}\text { PVAc } \\
\text { wt/wt } \%\end{array}$ & $\underset{10 \% w t / w t}{\text { Amine }}$ & & & & & & \\
\hline M1 & 100 & - & - & - & - & - & - & 535.13 & 570.48 \\
\hline M2 & - & 100 & - & - & - & 318.54 & 355.38 & - & - \\
\hline M3 & 95 & 5 & \multirow{4}{*}{ MDEA } & 248.42 & 272.41 & 360.42 & 370.60 & 533.29 & 566.94 \\
\hline M4 & 90 & 10 & & 246.12 & 270.73 & 352.44 & 365.51 & 530.84 & 565.33 \\
\hline M5 & 85 & 15 & & 245.96 & 267.25 & 351.82 & 364.97 & 526.61 & 558.80 \\
\hline M6 & 80 & 20 & & 244.15 & 261.32 & 345.71 & 355.87 & 525.07 & 557.43 \\
\hline
\end{tabular}

At the end of the degradation, almost $20-25 \%$ residual remained. Nevertheless, these results agreed with prior studies [30]. For an effective separation, the polymer should have good interaction in the blend and the important factors, which affect the properties and performance of the membrane are prearrangement of chemical groups attached to the main chain are also some of molecular structure and specific nature. In comparison, alkanol amines decompose at a lower temperature than PSU/PVAc because of the substitution of $\mathrm{NH}^{+}$group.

\section{Spectral Analysis of Enhanced Polymeric Blend Membrane}

Figure 7 (a) shows the FTIR for based PSU membrane with the functional group $\mathrm{S}=\mathrm{O}, \mathrm{CSO}_{2} \mathrm{C}, \mathrm{C}-\mathrm{O}, \mathrm{C}_{6} \mathrm{H}_{6}$ and the $\mathrm{OH}$ aliphatic and aromatic stretch. In based PSU membrane, the $\mathrm{S}=\mathrm{O}$ sulfone group was symmetric for the PSU wave length, (1150.00-1100.00 $\left.\mathrm{cm}^{-1}\right)$; give the characteristic peak at $1125.89 \mathrm{~cm}^{-1}$ without any substantial change caused by vibration stretching. The $\mathrm{CSO}_{2} \mathrm{C}$ asymmetric stretch peak seems at $1323.53 \mathrm{~cm}^{-1}$ due to hydrogen-bondaccepting groups with repeating unit at the ortho position [31]. The C-O asymmetric stretch peak in PSU (1260$1000 \mathrm{~cm}^{-1}$ ) shifted to $1018.45 \mathrm{~cm}^{-1}$ attributable to hydrogen shift bonding, and the region is associated with the benzene ring stretching mode [32]. The $\mathrm{C}_{6} \mathrm{H}_{6}$ ring stretch (wave number $1587.00-1489.00 \mathrm{~cm}^{-1}$ ) peaked at $1579.33 \mathrm{~cm}^{-1}$ as a slight change but otherwise endured stable. The $\mathrm{OH}$ aliphatic stretch (wave number $2886.00 \mathrm{~cm}^{-1}$ ) band arisen at $2880.15 \mathrm{~cm}^{-1}$ because of the weak electro-negativity of the $\mathrm{OH}^{-}$ion. The delocalization of the structure is accountable for the stability of its mechanical properties and its good strength values against oxidative degradation although at high temperatures. Due to the existence of aromatic rings in polysulfone polymer is susceptible to a sulfonation reaction, $-\mathrm{SO}_{3} \mathrm{H}$ associations incorporate into their structure [31].

Figure 7 (b) shows the FTIR for based PVAc membrane. This figure represent the functional group that are $\mathrm{C}-\mathrm{O}, \mathrm{C}-\mathrm{H}$ and $\mathrm{C}=\mathrm{O}$. The wavelength of $\mathrm{C}=\mathrm{O}$ is $1760 \mathrm{~cm}^{-1}$ to $1600 \mathrm{~cm}^{-1}$, the peak seems on $1630.65 \mathrm{~cm}^{-1}$. The carboxylic group C-O, a peak appears at $1025.72 \mathrm{~cm}^{-1}$ due to interactions between hydrogen bonding [33, 34]. The C-H group in phenyl ring substitution bands wavelength is $\left(870.00-675.00 \mathrm{~cm}^{-1}\right)$, the band appears on $801.85 \mathrm{~cm}^{-1}$ caused by symmetric stretching in $\mathrm{CH}_{3}[22,23]$. This band is due to the vibration of symmetric angular deformation outside the C-H plan complex. 
Journal of Thermal Engineering, Research Article, Vol. 7, No. 2, Special Issue 13, pp. 71-82, February, 2021

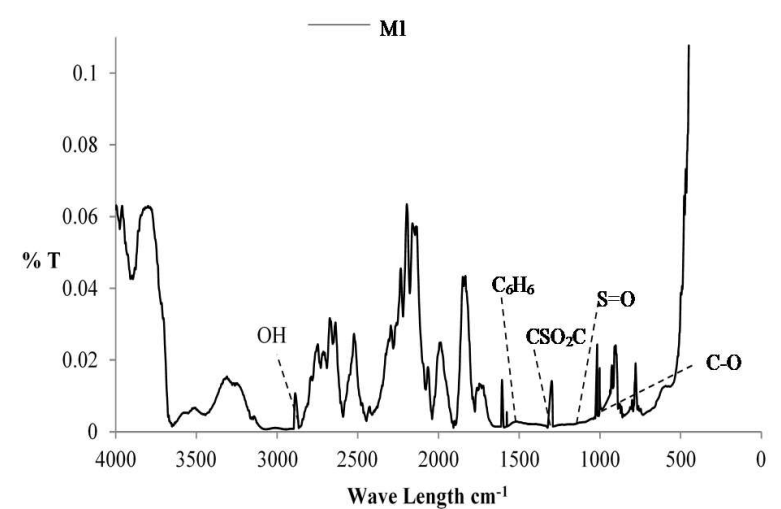

a)

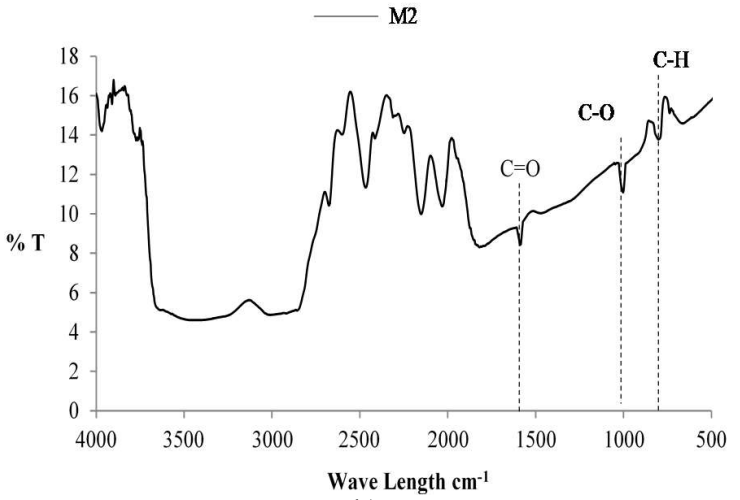

b)

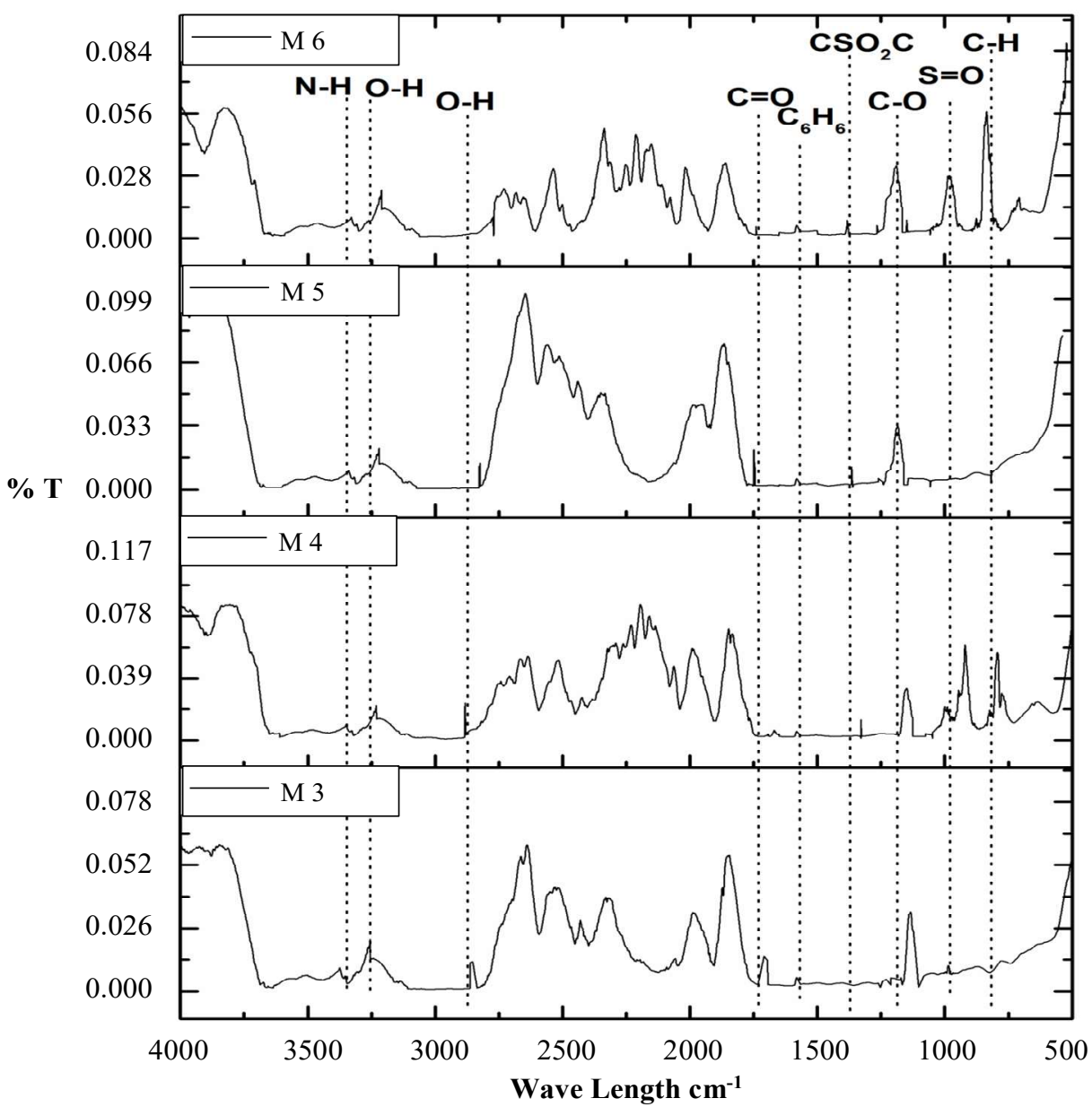

c)

Figure 7. FTIR of spectral analysis a) based PSU membrane, b) Based PVAc membrane,

c) Comparative FTIR spectra of the polymeric blend membranes with MDEA

Figure 7 (c) indicates the addition of 10wt. \% MDEA in PSU/PVAc blend of different compositions all previous functional groups $\left(\mathrm{S}=\mathrm{O}, \mathrm{CSO}_{2} \mathrm{C}, \mathrm{C}-\mathrm{O}, \mathrm{C}_{6} \mathrm{H}_{6}, \mathrm{C}-\mathrm{H}\right.$ and $\left.\mathrm{C}=\mathrm{O}\right)$ were present in the original position. The new peak C-N appears 1207.21-1241.65 cm-1 for M3 to M6. New absorption bands observed in M3 to M6 membranes in the region of $3374.21 \mathrm{~cm}^{-1}-3378.29 \mathrm{~cm}^{-1}$ are because of N-H stretch band of MDEA. The absorption bands at 3240.93- 
$3270.11 \mathrm{~cm}^{-1}$ (M3 to M6) are attributed to O-H group of MDEA. The change in wavenumber can be described by the formation of hydrogen bonds among -OH of methyl diethanolamine (MDEA) and oxygen atoms of the sulfone group [31]. It has observed that all the synthesized membranes have the same spectrum, showed that there was no chemical interaction among PSU/PVAc and MDEA hydrogen interactions.

Interestingly, on account of blends with at least some level of compatibility, the shifts of certain significant bands to other frequencies point toward the presence of specific interactions happening among the characteristic groups of the base PSU/PVAc polymers and MDEA. The summarised form of different shifts in the FTIR spectra are presented in Table 3 and supports the development of the interactions among the polymers which indicates their miscibility in the form of blended membranes $[22,23,35,36]$. The limited degree of peak shifting revealed by FTIR studies confirmed the miscibility of the tested polymer blends.

Table 3. Summary of the FTIR spectral of enhanced polymeric blend membranes [22, 23, 35-37]

\begin{tabular}{|l|l|l|l|l|}
\hline \multirow{5}{*}{ Polymer } & Spectral Assignment & \multicolumn{1}{|c|}{$\begin{array}{c}\text { Wave Number } \\
\mathbf{c m}^{-1}\end{array}$} & $\begin{array}{l}\text { Based } \\
\text { membranes } \\
\text { Observed wave } \\
\text { number } \mathbf{c m}^{-1}\end{array}$ & $\begin{array}{l}\text { PSU/PVAc/MDEA } \\
\text { blend membranes } \\
\text { Observed wave } \\
\text { number } \mathbf{c m}^{-1}\end{array}$ \\
\hline \multirow{5}{*}{ PSU } & $\begin{array}{l}\text { S=O symmetric stretch } \\
\text { (Sulfone) }\end{array}$ & $1150-1100$ & 1125.89 & $1105.35-1130.74$ \\
\cline { 2 - 5 } & $\begin{array}{l}\text { CSO }{ }_{2} \text { C (Dimethyl } \\
\text { sulfone) }\end{array}$ & $\begin{array}{l}1322, \\
1370-1250\end{array}$ & 1323.53 & $1307.28-1324.63$ \\
\cline { 2 - 5 } & $\begin{array}{l}\text { C-O asymmetric stretch } \\
\text { (Carboxylic) }\end{array}$ & $\begin{array}{l}1244, \\
1260-1000\end{array}$ & 1018.45 & $1039.92-1052.54$ \\
\cline { 2 - 5 } & $\begin{array}{l}\text { C6 } \text { H }_{6} \text { ring stretch } \\
\text { (Benzene) }\end{array}$ & $1587-1489$ & 1579.33 & $1542.67-1569.39$ \\
\cline { 2 - 5 } & $\begin{array}{l}\text { OH aromatic and aliphatic } \\
\text { stretch }\end{array}$ & $\begin{array}{l}2971,2938 \text { and } \\
2886\end{array}$ & 2880.15 & $2871.72-2889.44$ \\
\hline \multirow{5}{*}{ PVAc } & C=O stretch (Ketone) & $1736,1760-1600$ & 1630.65 & $1734.66-1744.27$ \\
\cline { 2 - 5 } & C-O asymmetric stretch & $1244,1260-1000$ & 1025.72 & $1039.92-1052.54$ \\
\cline { 2 - 5 } & $\begin{array}{l}\text { C-H phenyl ring } \\
\text { substitution band }\end{array}$ & $870-675,850$ & 801.85 & $819.83-867.81$ \\
\hline \multirow{5}{*}{ MDEA } & C-N stretch & $1340-1020$ & - & $1207.21-1241.65$ \\
\cline { 2 - 5 } & N-H stretch & $3500-3300$ & - & $3374.21-3378.29$ \\
\cline { 2 - 5 } & O-H stretch & $3640-3160$ & - & $3240.93-3270.11$ \\
\hline
\end{tabular}

Moreover, there was no formation of intermediates or cross-linking and the frequency shifts observed were peaks that characterised diaryl sulfone, $\mathrm{C}-\mathrm{O}, \mathrm{C}=\mathrm{O}$ and $\mathrm{N}-\mathrm{H}$ groups of PSU/PVAc/MDEA [31]. In these spectral variations point to molecular interactions between the polymer components in the blends, highlighting their compatibility [22, 36, 38]. These observations are in good agreement with previous studies [39-44].

\section{CONCLUSION}

Enhanced Polymeric Blend membrane has been successfully established. The cross sections of blended membranes showed packed bed of spheres that were highly packed. The cross sections also showed good interaction amongst PSU, PVAc polymers with MDEA amine. The kinetic analysis performed on the developed membranes revealed that the thermal degradation temperature decrease with the increase the PVAc contents in PSU. FTIR analysis confirmed miscibility as few shifts in spectra were observed. Moreover, no evidence of cross-linking or intermediate species formations was observed. This enhancement in the properties has been achieved due to the addition of MDEA amine in PSU/PVAc blend membranes. Future studies to replace the MDEA amine by di-iso propyl amines (DIPA). 
Journal of Thermal Engineering, Research Article, Vol. 7, No. 2, Special Issue 13, pp. 71-82, February, 2021

\section{ACKNOWLEDGEMENT}

The authors would like to acknowledge the Universiti Teknologi PETRONAS for supporting this research work and the NED University of Engineering \& Technology, Karachi, Pakistan for financial support to Asim Mushtaq studying at this University.

$\begin{array}{ll}\text { NOMENCLATURE } \\ \text { DMAc } & \text { Dimethyl acetamide } \\ \text { DEA } & \text { Diethanolamine } \\ \text { EPBM } & \text { Enhanced Polymeric Blend Membranes } \\ \text { GPU } & \text { Gas permeation unit } \\ \text { MEA } & \text { Monoethanolamine } \\ \text { PSU } & \text { Polysulfone } \\ \text { PVAc } & \text { Polyvinyl acetate } \\ T_{g} & \text { Glass transition temperature }\end{array}$

\section{REFERENCES}

[1] Yang H, Xu Z, Fan M, Gupta R, Slimane RB, Bland AE, Wright I. Progress in carbon dioxide separation and capture: A review. Journal of Environmental Sciences. 2008; 20 (1): 14-27. doi: 10.1016/s10010742(08)60002-9.

[2] Bernardo P, Clarizia G. 30 years of membrane technology for gas separation. Chemical Engineering Transactions 2013; 32: 1999-2004. https://doi.org/10.3303/CET1332334.

[3] Miller SJ, Koros WJ, Vu DQ. Mixed matrix membrane technology: enhancing gas separations with polymer/molecular sieve composites. Studies in Surface Science and Catalysis 2007; 170: 1590-1596. https://doi.org/10.1016/S0167-2991(07)81035-4. doi: 10.1002/app.30578.

[4] Van der Bruggen B. Chemical modification of polyethersulfone nanofiltration membranes: A review. Journal of Applied Polymer Science. 2009; 114 (1): 630-642. doi: 10.1002/app.30578.

[5] Wang Z, Chen T, Xu J. Gas transport properties of novel cardo poly (aryl ether ketone) s with pendant alkyl groups. Macromolecules. 2000; 33 (15): 5672-5679. https://doi.org/10.1021/ma9921807.

[6] Torres-Trueba A, Ruiz-Treviño FA, Luna-Bárcenas G, Ortiz-Estrada CH. Formation of integrally skinned asymmetric polysulfone gas separation membranes by supercritical $\mathrm{CO}_{2}$. Journal of Membrane Science. 2008; 320 (1-2): 431-435. doi: 10.1016/j.memsci.2008.04.024.

[7] Bos A, Punt IGM, Wessling M, Strathmann H. $\mathrm{CO}_{2}$-induced plasticization phenomena in glassy polymers. Journal of Membrane Science. 1999; 155 (1): 67-78. https://doi.org/10.1016/S0376-7388(98)00299-3.

[8] Zhang Y, Sunarso J, Liu S, Wang R. Current status and development of membranes for $\mathrm{CO}_{2} / \mathrm{CH}_{4}$ separation: A review. International Journal of Greenhouse Gas Control. 2013; 12: 84-107. doi: 10.1016/j.ijggc.2012.10.009.

[9] Robeson LM, Liu Q, Free-man BD, Paul DR. Comparison of transport properties of rubbery and glassy polymers and the relevance to the upper bound relationship. Journal of Membrane Science. 2015; 476: 421431. doi: 10.1016/j.memsci.2014.11.058.

[10] Wessling M, Schoeman S, Boomgaard Tvd, Smolders CA. Plasticization of gas separation membranes. Gas Separation \& Purification. 1991; 5 (4): 222-228. doi: 0950-4214/91/040222-07.

[11] Mondal MK. Absorption of carbon dioxide into a mixed aqueous solution of diethanolamine and piperazine. Indian Journal Chemical Technology. 2010; 17: 431-435.

[12] Speyer D, Ermatchkov V, Maurer G. Solubility of carbon dioxide in aqueous solutions of Nmethyldiethanolamine and piperazine in the low gas loading region. Journal of Chemical \& Engineering Data 2009; 55 (1): 283-290. https://doi.org/10.1021/je9003383.

[13] Loo Sv, Elk EPv, Versteeg GF. The removal of carbon dioxide with activated solutions of methyl-diethanolamine. Journal of Petroleum Science and Engineering. 2007; 55 (1-2): 135-145. doi: 10.1016/j.petrol.2006.04.017.

[14] Baker RW. Membrane Technology and Applications: Overview of membrane science and technology. 3 ed. New York: Willey; 2012. 1-14. https://doi.org/10.1002/9781118359686.ch1.

[15] Scott K. Handbook of industrial membranes. Oxford: Elsevier; 1995.

[16] Barton AF. Handbook of solubility parameters and other cohesion parameters. 2nd ed. Florida: CRC Press; 1991. 
[17] Barton AF. Handbook of Poylmer-Liquid Interaction Parameters and Solubility Parameters. 1st ed. Florida: CRC Press; 1990. https://doi.org/10.1002/pat.1992.220030107.

[18] Verevkin SP. Thermochemistry of amines: experimental standard molar enthalpies of formation of some aliphatic and aromatic amines. Journal of Chemical Thermodynamics 29. 1997; 8: 891-899. https://doi.org/10.1006/jcht.1997.0212.

[19] Cheremisinoff NP. Industrial Organic Solvents. Industrial Solvents Handbook. Second Edition. New York: Marcel Dekker; 2003. 29-32.

[20] Leiknes TO. The development of a biofilm membrane bioreactor [PhD. Thesis]. KSA: PhD Dissertation, King Abdullah University of Science and Technology 2008. https://doi.org/10.1016/j.desal.2005.12.049.

[21] Aroon MA, Ismail AF, Montazer-Rahmati MM, Matsuura T. Morphology and permeation properties of polysulfone membranes for gas separation: Effects of non-solvent additives and co-solvent. Separation and Purification Technology. 2010; 72 (2): 194-202. doi: 10.1016/j.seppur.2010.02.009.

[22] Rafiq S, Man Z, Maitra S, Maulud A, Ahmad F, Muhammad N. Preparation of asymmetric polysulfone/polyimide blended membranes for $\mathrm{CO}_{2}$ separation. Korean Journal of Chemical Engineering. 2011; 28 (10): 2050-2056. doi: 10.1007/s11814-011-0053-1.

[23] Devi KBR, Madivanane R. Normal coordinate analysis of polyvinyl acetate. IRACST-Engineering Science and Technology. 2012; 2 (4): 795-799.

[24] Feng S, Ren J, Li H, Hua K, Li X, Deng M. Polyvinyl acetate/poly(amide-12-b-ethylene oxide) blend membranes for carbon dioxide separation. Journal of Energy Chemistry. 2013; 22 (6): 837-844. doi: 10.1016/s2095-4956(14)60262-x.

[25] Mansourpanah Y, Gheshlaghi A. Effects of adding different ethanol amines during membrane preparation on the performance and morphology of nanoporous PES membranes. Journal of Polymer Research. 2012; 19 (12): 1-7. doi: 10.1007/s10965-012-0013-4.

[26] Zhao Y-L, Jones WH, Monnat F, Wudl F, Houk KN. Mechanisms of thermal decompositions of polysulfones: A DFT and CBS-QB3 study. Macromolecules. 2005; 38 (24): 10279-10285. https://doi.org/10.1021/ma051503y.

[27] Holland BJ, Hay JN. The thermal degradation of poly (vinyl acetate) measured by thermal analysis-Fourier transform infrared spectroscopy. Polymer. 2002; 43 (8): 2207-2211. https://doi.org/10.1016/S00323861(02)00038-1.

[28] Blazevska-Gilev J, Spaseska D. Thermal degradation of PVAc. Journal of the University of Chemical Technology and Metallurgy. 2005; 40 (4): 287-290.

[29] Simon P, Rybar M. Kinetics of polymer degradation involving the splitting off of small molecules: Part 8. Thermal degradation of polyvinyl esters. Polymer Degradation and Stability 1992; 38 (3): 255-259. https://doi.org/10.1016/0141-3910(92)90121-K.

[30] Pourya M, Ibrahim NA, Yunus WMZW, Yusof NA. Separation of $\mathrm{CO}_{2}$ from $\mathrm{CH}_{4}$ by pure PSF and PSF/PVP blend membranes: Effects of type of nonsolvent, solvent, and PVP concentration. Journal of Applied Polymer Science. 2013; 130 (2): 1139-1147. doi: 10.1002/app.39288.

[31] Linares A, Acosta JL. Structural characterization of polymer blends based on polysulfones. Journal of Applied Polymer Science. 2004; 92 (5): 3030-3039. https://doi.org/10.1002/app.20263.

[32] Stuart BH. Polymer analysis. Australia: John Wiley \& Sons; 2008.

[33] Ahmed I, Idris A, Noordin MY, Rajput R. High Performance Ultrafiltration Membranes Prepared by the Application of Modified Microwave Irradiation Technique. Industrial \& Engineering Chemistry Research. 2011; 50 (4): 2272-2283. doi: 10.1021/ie1017223.

[34] BumPark H, Kim CK, Lee YM. Gas separation properties of polysiloxane/polyether mixed soft segment urethane urea membranes. Journal of Membrane Science. 2002; 204 (1): 257-269. https://doi.org/10.1016/S0376-7388(02)00048-0.

[35] Siesler HW. Rheo-optical Fourier-Transform infrared spectroscopy: Vibrational spectra and mechanical properties of polymers. In Analysis/Networks/Peptides. $\quad$ Springer. $1984:$ 1-77. https://doi.org/10.1007/BFb0017101.

[36] Raslan R, Mohammad AW. Polysulfone/Pluronic F127 Blend Ultrafiltration Membranes: Preparation and Characterizations. Journal of Applied Sciences. 2010; 10 (21): 2628-2632. DOI: 10.3923/jas.2010.2628.2632.

[37] Shillady D. Essentials of physical chemistry. New York: Taylor \& Francis Group; 2011. 291-294.

[38] Jiang L, Chung T, Kulprathipanja S. An investigation to revitalize the separation performance of hollow fibers with a thin mixed matrix composite skin for gas separation. Journal of Membrane Science. 2006; 276 (1): 113 125. doi: 10.1016/j.memsci.2005.09.041. 
[39] Gholinia M, Moosavi SK, Gholinia S, Ganji DD. Numerical simulation of nanoparticle shape and thermal ray on a $\mathrm{CuO} / \mathrm{C}_{2} \mathrm{H}_{6} \mathrm{O}_{2}-\mathrm{H}_{2} \mathrm{O}$ hybrid base nanofluid inside a porous enclosure using Darcy's law. Heat TransferAsian Research. 2019; 48 (7): 3278-3294. https://doi.org/10.1002/htj.21541.

[40] Gholinia M, Moosavi SK, Pourfallah M, Gholinia S, Ganji DD.. A numerical treatment of the $\mathrm{TiO}_{2} / \mathrm{C}_{2} \mathrm{H}_{6} \mathrm{O}_{2}-$ $\mathrm{H}_{2} \mathrm{O}$ hybrid base nanofluid inside a porous cavity under the impact of shape factor in MHD flow. International Journal of Ambient Energy. 2019; 5 (21): 1-8. https://doi.org/10.1080/01430750.2019.1614996.

[41] Gholinia M, Armin M, Ranjbar AA, Ganji DD. Numerical thermal study on $\mathrm{CNTs}_{\mathrm{s}} / \mathrm{C}_{2} \mathrm{H}_{6} \mathrm{O}_{2}-\mathrm{H}_{2} \mathrm{O}$ hybrid base nanofluid upon a porous stretching cylinder under impact of magnetic source. Case Studies in Thermal Engineering. 2019; 14 (1): 100490-100495. https://doi.org/10.1016/j.csite.2019.100490.

[42] Ghadikolaei SS, Gholinia M, Hoseini ME, Ganji DD. Natural convection MHD flow due to $\mathrm{MoS}_{2}-\mathrm{Ag}$ nanoparticles suspended in $\mathrm{C}_{2} \mathrm{H}_{6} \mathrm{O}_{2} \mathrm{H}_{2} \mathrm{O}$ hybrid base fluid with thermal radiation. Journal of the Taiwan Institute of Chemical Engineers. 2019; 97 (1): 12-23. https://doi.org/10.1016/j.jtice.2019.01.028.

[43] Ghadikolaei SS, Gholinia M. Terrific effect of $\mathrm{H}_{2}$ on 3D free convection MHD flow of $\mathrm{C}_{2} \mathrm{H}_{6} \mathrm{O}_{2} \mathrm{H}_{2} \mathrm{O}$ hybrid base fluid to dissolve $\mathrm{Cu}$ nanoparticles in a porous space considering the thermal radiation and nanoparticle shapes effects. International Journal of Hydrogen Energy. 2019; 44 (31): 17072-17083. https://doi.org/10.1016/j.ijhydene.2019.04.171.

[44] Gholinia M, Pourfallah M, Chamani HR. Numerical investigation of heat transfers in the water jacket of heavy duty diesel engine by considering boiling phenomenon. Case Studies in Thermal Engineering. $2018 ; 12$ (1): 497-509. https://doi.org/10.1016/j.csite.2018.07.003. 